\title{
New Water-Oil Displacement Efficiency Prediction Method
}

\author{
Haohan Liu ${ }^{1,2, *}$ \\ ${ }^{I}$ Post-Doctoral Research Station, Southwest Petroleum University, Chengdu, China; ${ }^{2}$ Innovation and Practice Base for \\ Post-Doctors, Sichuan College of Architectural Technology, Deyang, China
}

\begin{abstract}
There is seldom research on describing the changing trend of water-oil displacement efficiency based on time and water drive frontal position. In previous study, our team gave the theoretical expression of water saturation in oilwater fluid flow area based on time and distance. In this work, we mainly focus on the prediction of water-oil displacement efficiency combining the permeability experiment and theoretical expression of water saturation. This new expression gives the micro water-oil displacement efficiency in different frontal position and time. The prediction results show: that the predicting accuracy is high and practicable, and we can shorten the time and cost of experiment and this prediction method is meaningful in guiding the actual oilfield development.
\end{abstract}

Keywords: Permeability experiment, prediction, water-oil displacement efficiency, water saturation.

\section{INTRODUCTION}

Buckley-Leverett (1942) proposed the Buckley-Leverett equation [1], and it has been used in water saturation prediction experimentally, so theoretical expression of water saturation based on time and distance needs to be established. Many scholars are engaged in water saturation description, and already made some progress. The previous study was based on the experimental method, Archie (1942) established a formula of water saturation adaptive to these pure sandstone reservoirs [2]; Poupon's work (1971) [3] was based on Simandoux's which was done in 1983 [4], where an equation of water saturation was given. Fertl (1982) [5] and Dewan (1998) [6] further developed the above-mentioned equation. Yao (1993) et al. used the analytical forecasting method to study the water saturation of reservoir [7]; Zhang et al. (2008) theoretically deduced the relation between electric resistivity and water saturation [8]; Wang et al. (2010) [9] and Li (2010) [10] also studied the water saturation of oil reservoirs with the experimental method, respectively. However, the theoretical expression of water saturation based on time and distance still needs to be studied. Considering the Buckley-Leverett equation and related mathematical model, and introducing Vieta's theorem to the differentiation of water cut, Liu $[11,12]$ established the theoretical expression of water saturation based on time and distance. This new expression can be used to predict the water-oil displacement efficiency. At present, there is seldom theoretical research on water-oil displacement efficiency prediction method based on time and distance. Hence, study on water-oil displacement efficiency based on time and distance gets theoretical and practical value.

\section{PARAMETERS CONFIRMATION IN NEW WATER SATURATION EQUATION}

Combining relational expression between relative permeability and water saturation with the fractional flow equation

\footnotetext{
*Address correspondence to this author at the Post-doctoral research station, southwest petroleum university, Chengdu, China; Tel: 028-83037760; Fax:028-83037760; E-mail: Tsinghua616@163.com
}

produced an expression of water cut changed by water saturation; Introducing Vieta's theorem to the differentiation of water cut gave a theoretical expression of water saturation in oil-water fluid flowarea; Introducing the concept of frontal water saturation to these expressions gave the continuous expression of water saturation [12], it is,

$$
\begin{aligned}
S_{w}= & \frac{1}{b} \ln \left(2 \phi A\left(x-x_{0}\right) M a /-\left[2 \phi A\left(x-x_{0}\right)-b W(t)\right]+\right. \\
& \frac{b W(t) \sqrt{b\left[b-\frac{4 \phi A}{W(t)}\left(x-x_{0}\right)\right]}}{2 \phi A(M a+1)} \leq x-x_{0} \leq \frac{b W(t)}{4 \phi A} \\
S_{w}= & \frac{1}{1.52} \ln \frac{1880.8\left(x-x_{0}\right)}{45.6 t-420\left(x-x_{0}\right)+30 t \sqrt{\left.2.3104-\frac{42.56\left(x-x_{0}\right)}{t}\right]}}, \\
& 0.01982 t \leq x-x_{0} \leq 0.0543 t
\end{aligned}
$$

By taking the relative permeability experiments, the parameter of $a$ and $b$ in eq. (1) can be achieved with regression analysis method, the experiment procedure is given in Fig. (1).

\section{Experiment steps:}

1) Drill and cut cores;

2) Preparation of formation water and simulated oil;

3) Clean and load cores;

4) Measurement of air and water permeability;

5) Calculation of pore volume;

6) Establishment of irreducible water saturation;

7) Measurement of oil relative permeability;

8) The experimental data processing; 
9) Simulation of parameters $a$ and $b$ with regression method.

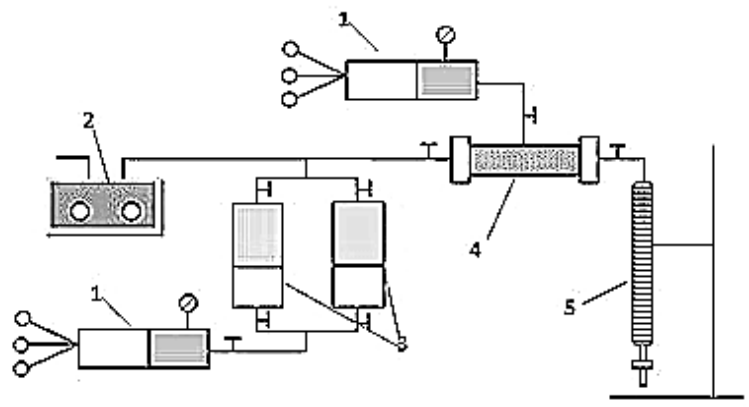

1-Displacement pump; 2-Vacuum pump; 3-Intermediate container; 4-Core holder; 5-oil and water metering device

Fig. (1). Relative permeability experiments procedure.

\section{PREDICTION OF WATER-OIL DISPLACEMENT EFFICIENCY}

\section{Prediction of Water-Oil Displacement Efficiency}

Definition of water-oil displacement efficiency gives

$E_{D}=\frac{S_{w}-S_{w r}}{1-S_{w r}}$

In previous time, the $E_{D}$ was changed by $S_{w}$, and in calculation, we can hardly obtain the micro water-oil displacement efficiency in different water drive front position. By introducing eq. (1) to eq. (2) gives

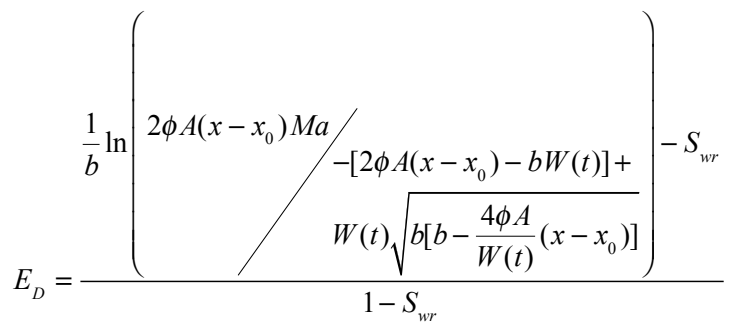

so we can use eq. (3) to calculate the $E_{D}$ chanced by time and distance. In other word, the $E_{D}$ in any water drive front position and time can be predicted now.

\section{Prediction of Water Cut}

It is known to us, one regression expression between permeability and saturation is,

$\frac{k_{r o}}{k_{r w}}=a e^{-b S_{w}}$

Here, $\frac{k_{r o}}{k}$ is the ratio of oil permeability and water permeability, $a^{r w}$ and $b$ are regression parameters.

Definition of water cut shows:

$f_{w}=\frac{Q_{w}}{Q_{w}+Q_{o}}=\frac{K_{w} / \mu_{w}}{K_{w} / \mu_{w}+K_{o} / \mu_{o}}=\frac{1}{1+\left(\frac{K_{o}}{K_{w}}\right)\left(\frac{\mu_{w}}{\mu_{o}}\right)}$

By introducing eq. (1) and eq. (4) to eq. (5) gives

$$
f_{w}=\frac{1}{\left.\left.1+a e^{-b\left[\frac { 1 } { b } \operatorname { l n } \left(2 \phi A\left(x-x_{0}\right) M a\right.\right.} /-\left[2 \phi A\left(x-x_{0}\right)-b W(t)\right]+W(t) \sqrt{b\left[b-\frac{4 \phi A}{W(t)}\left(x-x_{0}\right)\right]}\right)\right]\left(\frac{\mu_{w}}{\mu_{o}}\right)}
$$

Eq. (6) can be used to depict water cut changed by time and frontal distance, further, we can analyze the relation between water cut and water-oil displacement efficiency.

\section{APPLICATION AND DISCUSSION}

Given the experimental data of certain sandstone oil reservoir, see Table $\mathbf{1}$ and Table $\mathbf{2}$.

In Fig. (2), the bold line is the simulation line and the thin blue line is the experiment line, the simulation line is close to the experimental line;

In Fig. (3), the regression accuracy curve shows the simulation accuracy is higher than 0.97 , in other word, the regression error is 0.03 , this is acceptable. Here, In $a=9.52374, b=16.2878$. Using eq.(3) and eq.(5) gives Fig. (4) and Fig. (5):

Fig. (4) and Fig. (5) show: (1) the water in the block appears early, the time of oil production without water is short; the water cut improves quickly in the stage of water drive;

Table 1. Water and oil permeability data of a sandstone oil reservoir.

\begin{tabular}{|c|c|c|c|c|c|c|c|c|c|c|c|c|}
\hline $\boldsymbol{S}_{\boldsymbol{w}}, \mathbf{\%}$ & $\mathbf{0}$ & $\mathbf{1 0}$ & $\mathbf{2 0}$ & $\mathbf{3 0}$ & $\mathbf{4 0}$ & $\mathbf{5 0}$ & $\mathbf{6 0}$ & $\mathbf{7 0}$ & $\mathbf{7 5}$ & $\mathbf{8 0}$ & $\mathbf{9 0}$ & $\mathbf{1 0 0}$ \\
\hline \hline$K_{r o}$ & 1 & 1 & 1 & 0.94 & 0.80 & 0.44 & 0.16 & 0.045 & 0 & 0 & 0 & 0 \\
\hline$k_{r w}$ & 0 & 0 & 0 & 0.01 & 0.04 & 0.11 & 0.20 & 0.30 & 0.36 & 0.44 & 0.68 & 1 \\
\hline
\end{tabular}

Table 2. Practical development data of a sandstone oil reservoir.

\begin{tabular}{|c|c|c|c|c|c|c|}
\hline $\begin{array}{c}\text { Velocity Ratio of } \\
\text { Oil and Water }\end{array}$ & Porosity & $\begin{array}{c}\text { Reservoir } \\
\text { Width, } \mathbf{m}\end{array}$ & $\begin{array}{c}\text { Formation } \\
\text { Thickness, } \mathbf{m}\end{array}$ & $\begin{array}{c}\text { Single Well } \\
\text { Production, } \boldsymbol{m}^{\mathbf{3}} \boldsymbol{d}\end{array}$ & $\begin{array}{c}\text { Residual Oil } \\
\text { Saturation }\end{array}$ & $\begin{array}{c}\text { Irreducible } \\
\text { Water Saturation }\end{array}$ \\
\hline \hline 5 & 0.25 & 140 & $6 \mathrm{~m}$ & 30 & 0.28 & 0.25 \\
\hline
\end{tabular}

By using regression method gives 
the water cut improves slowly in the late stage of water drive; the effect of flooding is poor. (2) detailed changing trends of $E_{D}$ and $f_{w}$ are given. (3) the predicting result of $E_{D}$ is consistent with the experimental result of $E_{D}$ in water flood front position.

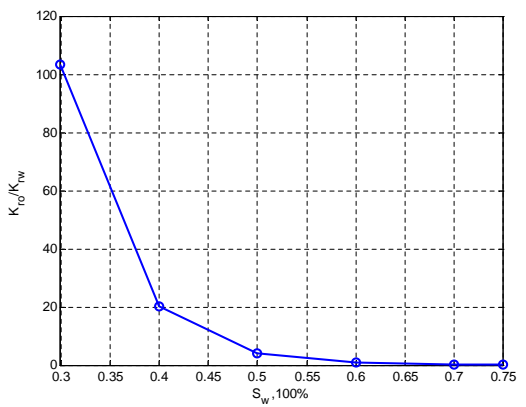

Fig. (2). Regression figure between Kro/Krw and Sw.

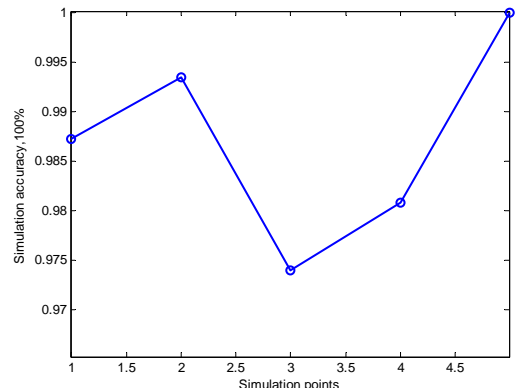

Fig. (3). Regression accuracy.

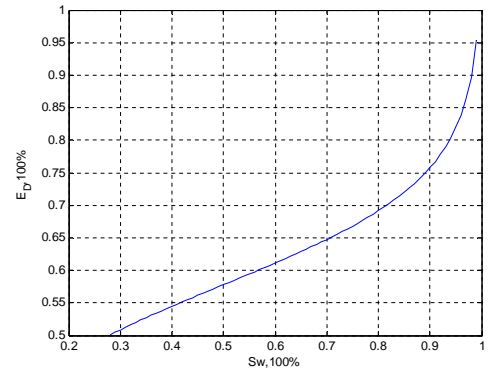

Fig. (4). The curve between water-oil displacement efficiency and water cut.

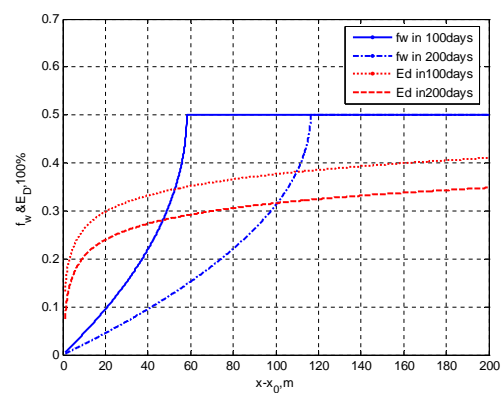

Fig. (5). $E_{D}$ and $f_{w}$ changed by time and frontal distance.

Here, the blue and pink curves are the curves on $E_{D}$ in 100 and 200days, separately; and the yellow triangle and the green intersect curves are the curves on $f_{w}$ in 100 and 200 days, separately.

Generally, the water in the block appears early, the oil and water production period is short, the water cut rises fast, the water channeling is severe and the water-oil displacement efficiency is low.
Note: The new $E_{D}$ prediction method is based on time and frontal position, it belongs to the microscopic percolation mechanism. While, the previous water-oil displacement efficiency prediction methods are based on water saturation or water cut, they belong to the macroscopic percolation mechanism.

\section{CONCLUSION}

1. New water-oil displacement efficiency and water cut predicting methods are changed by time and water flood frontal position.

2. The predicting result of $E_{D}$ is consistent with the experimental result of $E_{D}$ in water flood front position. The predicting accuracy is high and practicable, and we can shorten the time and cost of experiment and guide the practical development of oil field.

\section{CONFLICT OF INTEREST}

The authors confirm that this article content has no conflict of interest.

\section{ACKNOWLEDGEMENTS}

I would like to acknowledge reviewers and the editor for their helpful comments and suggestions that improved the manuscript significantly, this paper is funded by the China Postdoctoral Science Foundation funded project, No: 2014M562509XB, and Science and technology and intellectual property office of De Yang City, No: 2014ZZ095-6.

\section{NOMENCLATURE}

$k_{o} \quad=$ Oleic permeability, $\mathrm{mD}$

$k_{w} \quad=$ Water phase permeability, $\mathrm{mD}$

$a \quad=$ Linear intercept

$b \quad=$ Linear slope

$f_{w} \quad=$ Water cut or fractional flow rate

$M \quad=$ Viscosity ratio of water and oil

$\phi \quad=$ Porosity

$A \quad=$ Seepage flow area, $\mathrm{m}$

$S_{o r} \quad=$ Residual oil saturation

$S_{w r} \quad=$ Irreducible water saturation

$x_{f} \quad=$ Location of frontal zone, $\mathrm{m}$

$E_{D} \quad=$ Water-oil displacement efficiency $\frac{\partial f_{w}}{\partial S_{w}} \quad=\underset{\text { tion }}{\text { Ratio of change in water cut to change in satura- }}$

$x-x_{o}=$ Forwarding distance of any constant water saturation in seepage area, $\mathrm{m}$

\section{REFERENCES}

[1] S. E. Buckley, and M. C. Leverett, "Mechanism of fluid displacementsin sands", Transactions of the AIME vol. 146, pp. 107116,1942 .

[2] G. E. Archie, "The electrical resistivity log as an aid in determining some reservoir characteristics", Petroleum Transactions of AIME, vol. 146, pp. 54-62, 1942. 
[3] A. Poupon, M. E. Loy, and M. P. Tixier, "A contribution to electric $\log$ interpretation in shaly sands", Journal of Petroleum Technology, vol. 6, no. 6, pp. 27-34, 1954.

[4] P. Simandoux, "Dielectric measurements of porous media: Application to measurement of water saturations-study of the behavior of argillaceous formations", Oil \& Gas Science and Technology, vol. 18, no. SI, pp. 193-215, 1963.

[5] W. H. Fertl, and G. W. Hammack, "A comparative look at water saturation computation in shaly pay sands", The log Analyst, vol. 23, no. 2, pp. 12-20, 1982.

[6] J. Dewan, Essential of modern open-hole log interpretation. Oklahoma:Penn Well Publishing Company, 1988.

[7] H. S. Yao, and K. L. Xiang, "Analytical forecasting for water saturation of reservoirs", Systems Engineering-Theory and Practice, vol.3, pp. 137-142, 1993.
[8] C. M. Zhang, and Z. S. Zhang, "Study on theoretical deduction between water flooding resistance and water saturation and on numerical simulation", Science In China Press, vol. 22, no. 2, pp.151$156,2008$.

[9] X. Wang, and T.V. Nguyen, "An experimental study of the liquid water saturation level in the cathode gas diffusion layer of a PEM fuel cell”, Journal of Power Sources, vol. 197, pp. 50-56, 2012.

[10] L. Xiaoluo, and M. Liqing, "Study on calculation method of reservation water saturation by PND seizing pattern", Petroleum Instruments, vol. 3, pp. 24, 2010.

[11] Z. B. Liu, H. H. Liu, and X. F. Ding, "Theoretical Study of Water Saturation with Percolation Mechanics Method", The Open Petroleum Engineering Journal, vol. 5, pp.21-25, 2012.

[12] Z. B. Liu, H. H. Liu, and X. F. Ding, "Modified Theoretical Expression of Water Saturation in Oil-water Fluid Flow area", The Open Petroleum Engineering Journal, vol.6, pp.76-78, 2013.

Received: March 03, 2014

Revised: September 26, 2014

Accepted: November 20, 2014

(C) Haohan Liu; Licensee Bentham Open.

This is an open access article licensed under the terms of the Creative Commons Attribution Non-Commercial License (http://creativecommons.org/licenses/by-nc/3.0/) which permits unrestricted, non-commercial use, distribution and reproduction in any medium, provided the work is properly cited. 